\title{
How should I treat a left ventricular outflow tract-migrated balloon-expandable transcatheter heart valve?
}

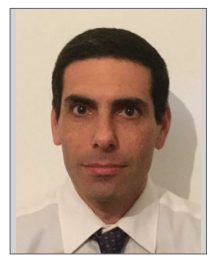

Israel M. Barbash ${ }^{1 *}$, MD; Andrada Bogdan¹, MD; Paul Fefer ${ }^{1}$, MD; Dan Spiegelstein², MD;

Ehud Raanani ${ }^{2}$, MD; Roy Beinart ${ }^{1}$, MD; Victor Guetta ${ }^{1}, \mathrm{MD}$; Amit Segev ${ }^{1}$, MD

1. The Heart Center, Chaim Sheba Medical Center, Tel Hashomer, Sackler School of Medicine, Tel Aviv

University, Israel; 2. The Department of Cardiac Surgery, Chaim Sheba Medical Center, Tel Hashomer, Sackler

School of Medicine, Tel Aviv University, Israel

Invited experts: Holger Eggebrecht ${ }^{3 *}, M D$; Andreas Zierer ${ }^{4}, M D ;$ Rafal Dworakowski ${ }^{5}, M D, P h D$;

Philip MacCarthy ${ }^{5}$, BSc, MBChB, PhD, FRCP

3. Cardioangiological Center Bethanien (CCB), Frankfurt, Germany; 4. Division of Thoracic and Cardiovascular Surgery,

J.W. Goethe University, Frankfurt, Germany; 5. Department of Cardiology, King's College Hospital, London, United Kingdom

The concluding section "How did I treat?" together with the complete references are published online at:

http://www.pcronline.com/eurointervention/95th_issue/278

\section{CASE SUMMARY}

BACKGROUND: A high surgical risk patient with severe aortic stenosis underwent transcatheter aortic valve implantation

INVESTIGATION: Transcatheter aortic valve implantation was performed uneventfully.

DIAGNOSIS: Early after the procedure, echocardiography study and aortography indicated that the implanted valve migrated into the left ventricular outflow tract.

MANAGEMENT: A second transcatheter aortic valve was implanted inside the migrated valve (TAV-in-TAV) while securing the position of the migrated valve.

KEYWORDS: aortic stenosis, migration, transcatheter aortic valve implantation

\section{PRESENTATION OF THE CASE}

An 85-year-old female patient with small body habitus (body mass index of $23.1 \mathrm{~kg} / \mathrm{m}^{2}$, body surface area of $1.5 \mathrm{~m}^{2}$ ) and medical history of lymphoma in remission and atrial fibrillation on new oral anticoagulants was referred to our institutional Heart Team for consideration for transcatheter aortic valve implantation (TAVI). The patient was in NYHA Class IV heart failure. Her echocardiogram showed normal left ventricular function, severe calcified aortic stenosis with valve area of $0.6 \mathrm{~cm}^{2}$, and peak/mean gradient of $61 / 36 \mathrm{mmHg}$. The patient was frail, her Society of Thoracic Surgeons (STS) risk score for mortality was 5.3\%, and her EuroSCORE II was 3.4\%. Accordingly, it was decided to proceed with TAVI using the transfemoral approach. Pre-procedural computed tomography showed mildly calcified aortic valve leaflets (Figure 1) with an aortic valve perimeter of $68.3 \mathrm{~mm}$ and mean diameter of $21.7 \mathrm{~mm}$. Due to right bundle branch block in her baseline electrocardiogram putting her at high risk for post-procedure complete heart block, a $23 \mathrm{~mm}$ SAPIEN XT transcatheter heart valve (Edwards Lifesciences, Irvine, CA, USA) was chosen for TAVI. The procedure was performed under conscious sedation and a satisfactory position of the SAPIEN XT valve was achieved (Figure 2). The procedure was completed uneventfully. Upon transfer of the patient from the catheterisation lab bed to the stretcher, the patient developed complete atrioventricular block and a temporary pacemaker was re-inserted. The patient was haemodynamically

*Corresponding author: Leviev Heart Center, Interventional Cardiology, Sheba Medical Center, Tel Hashomer 52621, Israel. E-mail: ibarbash@gmail.com 


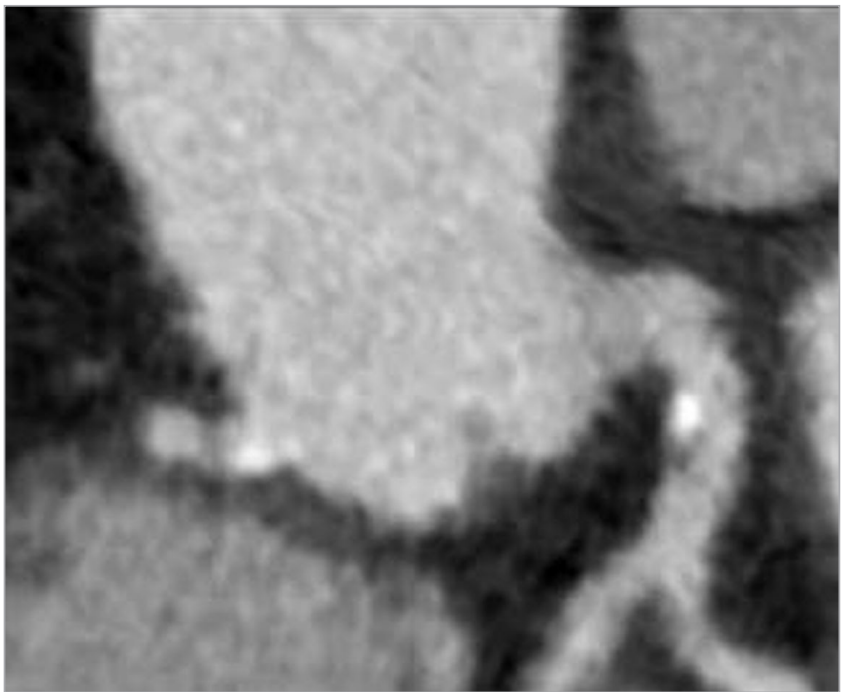

Figure 1. Gated computed tomography angiography of the aortic root demonstrating mild aortic valve leaflet calcifications.

stable. Transthoracic echocardiography performed on the morning post-procedure and aortic root angiography indicated that the SAPIEN XT valve became dislodged into the left ventricular outflow tract (LVOT) (Figure 3, Figure 4). While the dislodged valve was sitting in the LVOT, it was not clear how stable this position was and what the chances were that the valve would shift into the left ventricle either spontaneously or during a repeat valve-in-valve

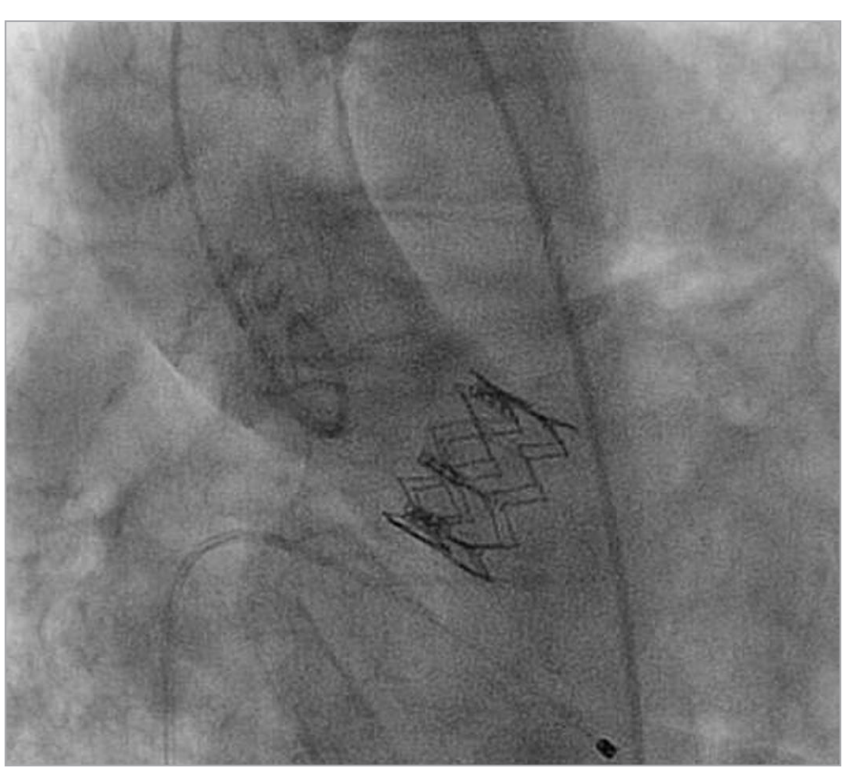

Figure 2. Aortic root angiography demonstrating final position of the implanted SAPIEN XT transcatheter heart valve.

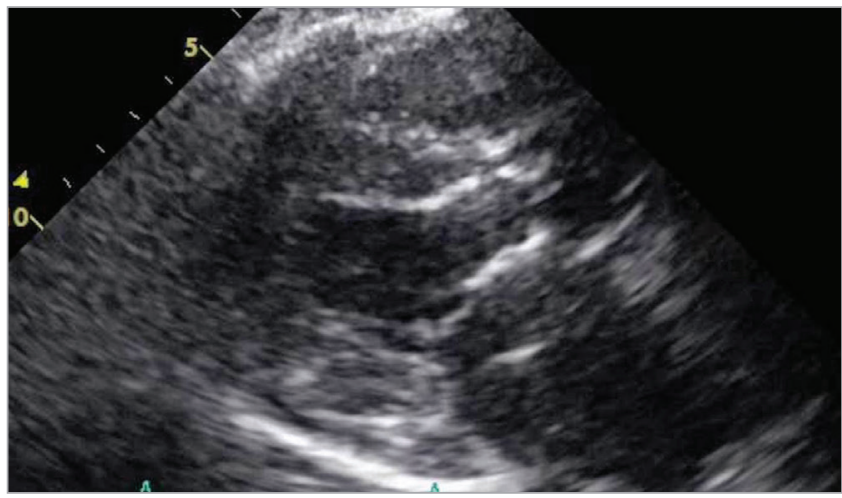

Figure 3. Transthoracic echocardiography showing a dislodged SAPIEN XT transcatheter heart valve in the left ventricular outflow tract.

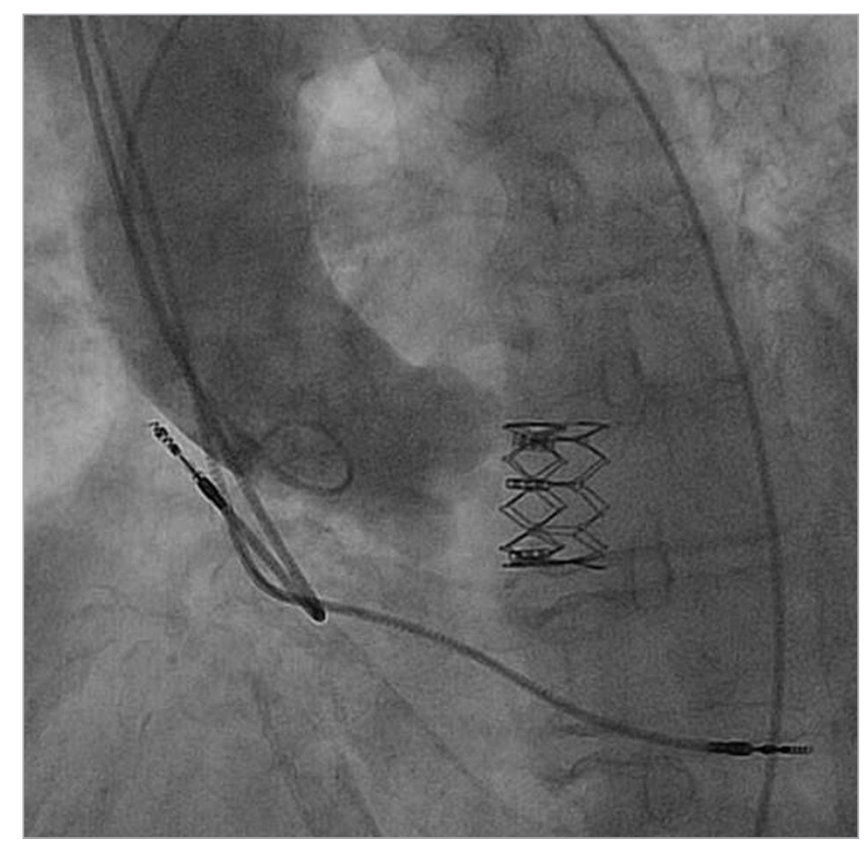

Figure 4. Aortic root angiography showing a dislodged SAPIEN XT transcatheter heart valve in the left ventricular outflow tract.

implantation. Due to the fact that the patient was completely stable with no signs of heart failure, no immediate intervention was attempted and a permanent pacemaker was implanted. Heart Team discussions reached an agreement that the patient's risk for surgery was extremely high.

What would be the options to treat a situation of an unstable, dislodged valve and the aortic stenosis of this patient with high surgical risk? 


\section{How would I treat?}

\section{THE INVITED EXPERTS' OPINION}

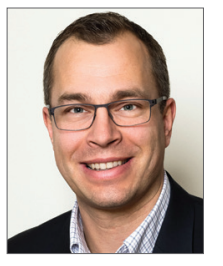

Holger Eggebrecht ${ }^{3 *}$, MD; Andreas Zierer ${ }^{4}, \mathrm{MD}$

3. Cardioangiological Center Bethanien (CCB), Frankfurt, Germany; 4. Division of Thoracic and

Cardiovascular Surgery, J.W. Goethe University, Frankfurt, Germany

Dislocation of the valve bioprosthesis is a rare complication of transcatheter aortic valve implantation (TAVI). Acute embolisation of the valve during the implantation procedure may occur in approximately $0.6 \%$ of patients ${ }^{1}$. While retrograde embolisation to the ascending aorta can often be managed interventionally (e.g., by retraction of the prosthesis and deployment into a more distal segment of the aorta), free embolisation to the left ventricle usually requires cardiac surgery for device removal. Migration of an initially correctly implanted TAVI valve is also a rare event $(0.3 \%)^{1}$, and may occur early $(<1 \text { day })^{2,3}$, but also as late as 43 to 63 days after TAVI ${ }^{4,5}$. Valve migration may be the cause of newly developed severe aortic regurgitation and cardiogenic shock ${ }^{4}$ or "restenosis" or "early degeneration" after TAVI ${ }^{6}$, but patients may also be asymptomatic as in the present case. Risk factors for device embolisation/migration comprise undersizing of the TAVI valve, minimal or non-uniformly distributed calcifications of the aortic annulus, suboptimal implant position too high or too low in the annulus, or native leaflet overhang post-deployment exerting downward force on the prosthesis ${ }^{4-7}$.

In the present case, TAVI was performed uneventfully in an 85 -year-old frail patient with significant comorbidities and an STS score of $5.3 \%$. Of note, only mild calcifications of the aortic valve were observed during pre-procedural computed tomography. The TAVI valve was implanted in a somewhat low position. Subsequently, early migration was noted on echocardiography in the haemodynamically stable patient. In this situation, the stability of the valve prosthesis in the LVOT is the most important question. Imminent free embolisation to the left ventricle mandates emergency cardiac surgery. Furthermore, symptoms of aortic stenosis may recur, as the native valve above the TAVI valve is still stenosed. Treatment options include re-do TAVI with implantation of a second valve ("valve-in-valve TAVI") to fixate the position of the migrated valve (and treat the remaining native aortic valve stenosis) $)^{3}$ or cardiac surgery for removal of the migrated valve with implantation of a surgical, potentially sutureless bioprosthesis. Although the patient was haemodynamically stable, the Heart Team (not surprisingly) considered the patient to be at extreme risk for surgery. While less invasive, transapical removal has been successfully performed for a TAVI valve freely embolised to the left ventricle $^{8}$, this approach may be difficult for a migrated valve still positioned within the LVOT. Therefore, valve-in-valve TAVI to fixate the migrated valve appears to be the most reasonable option ${ }^{3}$; however, particular care has to be taken to ensure that the migrated valve is not dislodged into the left ventricle during advancement of the second valve ${ }^{9}$, which would require bail-out cardiac surgery with even more increased risk. A transapical approach may therefore be preferred.

Of note, most of the published events of TAVI valve migration to the LVOT occurred (similar to the present case) with the use of the balloon-expandable Edwards SAPIEN XT prosthesis ${ }^{5,9}$. With the use of self-expanding valves, free embolisation to the LV is virtually impossible. With repositionable prostheses, the risks of embolisation/migration may even be further reduced.

\section{Conflict of interest statement}

The authors have no conflicts of interest to declare.

*Corresponding author: Cardioangiological Center Bethanien (CCB), Im Prüfling 23, 60389 Frankfurt, Germany. E-mail: h.eggebrecht@ccb.de 


\section{How would I treat?}

\section{THE INVITED EXPERTS' OPINION}

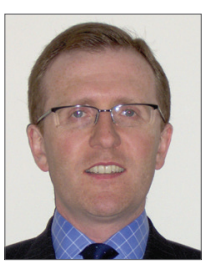

Rafal Dworakowski ${ }^{5}, \mathrm{MD}, \mathrm{PhD}$; Philip MacCarthy ${ }^{5 *}, \mathrm{BSc}, \mathrm{MBChB}, \mathrm{PhD}, \mathrm{FRCP}$

5. Department of Cardiology, King's College Hospital, London, United Kingdom

Barbash at al present a case of late migration of a balloon-expandable valve (SAPIEN XT) into the left ventricular outflow tract (LVOT). Valve migration is a rare complication of TAVI $(\sim 0.7 \%)$ and usually occurs immediately after or during valve deployment. Late valve migration is an extremely rare complication with very little experience reported.

In the presented case, the aortic valve was only mildly calcified with the aortic annulus measuring $22 \mathrm{~mm}$. A $23 \mathrm{~mm}$ SAPIEN XT valve prosthesis was used. It is worth noting here that valve sizing should not be based only on aortic annulus dimensions. Other anatomical features need to be considered, including the size of the aortic sinuses, severity/symmetry of aortic valve calcification and LVOT dimensions. The final valve position post-deployment was correct; hence, the subsequent movement from the annular position into the LVOT was most likely due to poor anchoring from the minimal calcification of the native aortic valve.

In the setting of TAVI, conversion to emergency open surgery carries a $50 \% 30$-day mortality ${ }^{10}$. However, there is one case report of a late SAPIEN valve embolisation into the LVOT ${ }^{11}$ which was successfully treated with open heart surgery. Given this patient's profile and surgical risk, we would consider emergency open surgery to be very high risk and would use it only as a last resort.

Our preferred remedy would be to perform a transcatheter valvein-valve procedure using a SAPIEN $326 \mathrm{~mm}$ valve. The deployment position is crucial. Transoesophageal echocardiography would be helpful to ensure that this second prosthesis is deployed high enough to catch and "pin back" the native valve leaflets but also low enough to land within and anchor the previously deployed SAPIEN XT. The main reason for choosing a larger valve is the fact that the aortic valve is only mildly calcified. We suspect that the $23 \mathrm{~mm}$ valve was undersized in the first place. The additional benefit of using a $26 \mathrm{~mm}$ over a $23 \mathrm{~mm}$ valve is the frame height, which is $20 \mathrm{~mm}$.

Ventricular embolisation of the SAPIEN valve following transapical TAVI has been reported with subsequent successful extraction via the same access ${ }^{8}$. This could be a second option to consider if our initial plan failed, but this would require new transapical access and would increase the risk to the patient.

\section{Conflict of interest statement}

P. MacCarthy is a proctor for Edwards Lifesciences. The other author has no conflicts of interest to declare. 


\section{How did I treat?}

\section{ACTUAL TREATMENT AND MANAGEMENT OF THE CASE}

Transcatheter heart valve embolisation is a rare event, ranging from $0.4-1.01 \% \%^{2,10,12-16}$. Most of the data regarding valve dislodgement comes from sub-analysis of the SOURCE registry and the PARTNER trial ${ }^{10,12}$. These data indicate that, in most cases, valve dislodgement is immediate and managed percutaneously with a TAVI-in-TAV positioned in the aortic annulus. Despite success in implanting a second valve, such procedures result in significantly higher rates of haemodynamic support and conversion to open heart surgery, also leading to worse outcomes.

Once valve dislodgement occurs, the main considerations in planning a treatment approach should be: (1) re-assessment of the patient risk for open heart surgery; (2) potential impingement on mitral valve leaflets, which will drive a decision towards open heart surgery; and (3) the level of the valve in the LVOT.

In the current case, if the dislodged SAPIEN XT valve ended up in a high LVOT position, it could have allowed transapical, antegrade implantation of a second SAPIEN valve, an approach that would have mitigated the risk of further ventricular valve movement. However, the low LVOT position in the current case required the use of a CoreValve ${ }^{\circledR}$ (Medtronic, Minneapolis, MN, USA) both to accomplish TAVI at the level of the native aortic valve annulus and to secure the original SAPIEN XT in position; however, the CoreValve currently can only be delivered retrogradely. In such cases when there is a need for retrograde implantation of CoreValve, there is a risk that the tip of the CoreValve delivery system will impact on the SAPIEN XT valve frame and, by doing so, push the SAPIEN XT further into the LV during the advancement of the CoreValve delivery system. Therefore, it is crucial to secure the position of the dislodged SAPIEN XT valve before and during positioning of the second valve.

The second TAVI procedure was performed 21 days after the original procedure. Using a transfemoral approach, an $18 \mathrm{Fr}$ sheath was inserted on one side and an $8 \mathrm{Fr}$ long sheath was inserted from the contralateral side. An initial attempt to stabilise the SAPIEN $\mathrm{XT}$ valve was performed by entrapping the valve with a snare wire to secure its position while advancing the CoreValve into position. For that purpose, through the $8 \mathrm{Fr}$ sheath, the native and dislodged SAPIEN XT valves were crossed using a straight wire which was then exchanged for a Torcon $\mathrm{NB}^{\circledR}$ Advantage Beacon ${ }^{\circledR}$ Tip
Angiographic Catheter (VS tip) (Cook Medical, Bloomington, IN, USA). Through this catheter a HI-TORQUE WHISPER coronary guidewire (Abbott Vascular, Santa Clara, CA, USA) was advanced behind the SAPIEN XT stent struts. The tip of the wire was snared in the ascending aorta by a GooseNeck snare (Covidien, Plymouth, $\mathrm{MN}, \mathrm{USA}$ ) and retrieved into the $8 \mathrm{Fr}$ sheath. Using this approach, it was possible to secure the SAPIEN XT valve from movement (Figure 5); however, the 0.014 inch wire was too weak and broke, so this approach was aborted. Despite the fact that the wire broke, we have shown that this approach is a feasible approach.

The bail-out plan was to control the tip of the CoreValve delivery system (manual retroflexion) so as to minimise any friction between the delivery system and the SAPIEN XT valve itself, or its frame. This was done by snaring the tip of the CoreValve delivery system via the contralateral $8 \mathrm{Fr}$ sheath. As the snare goes along the inner (smaller) curvature of the aortic arch (as opposed to the CoreValve which travels along the outer curvature) (Figure 6), by pulling the snare, one can bend back the tip of the delivery system

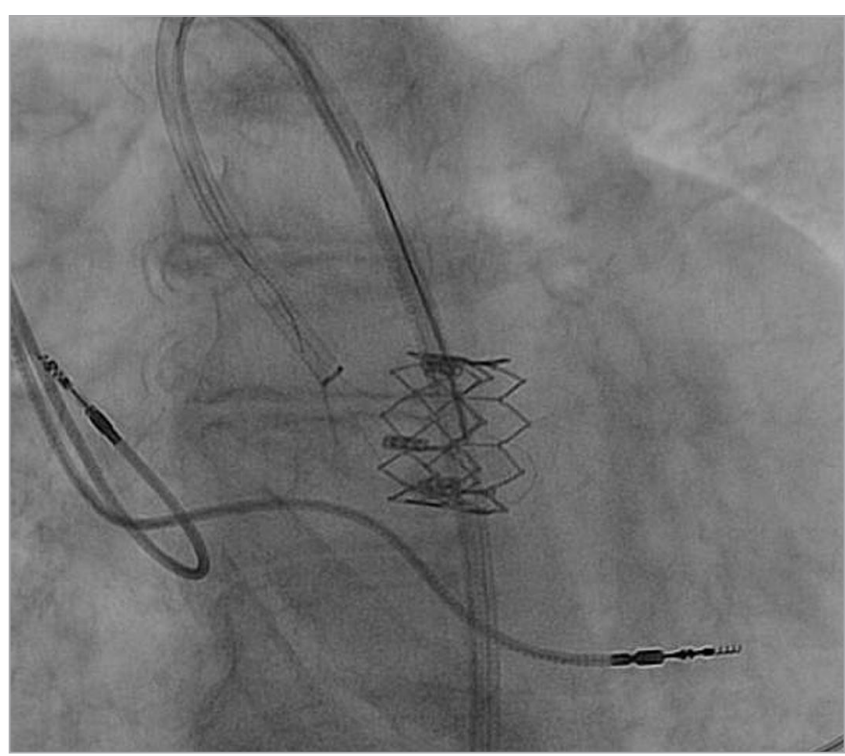

Figure 5. Attempted snaring of the SAPIEN XT valve in order to secure its location during the CoreValve valve-in-valve deployment. 


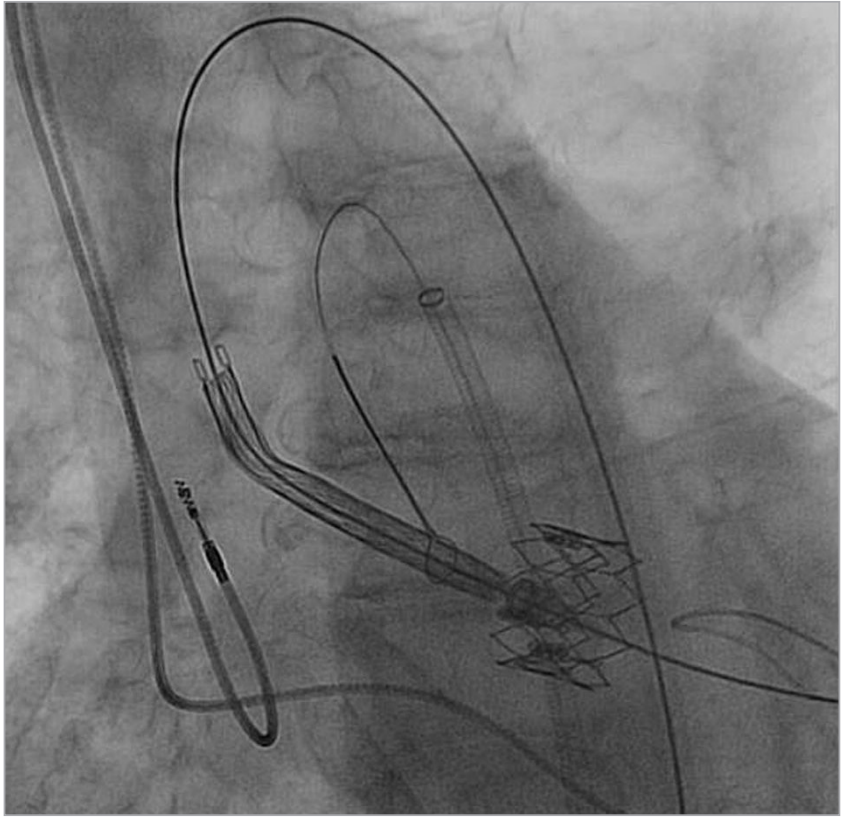

Figure 6. Snared CoreValve delivery system entering inside the SAPIEN XT valve while pulling tension is applied by the snare for the purpose of aligning the CoreValve in the centre of the SAPIEN XT valve.

so that it was aimed directly to the centre of the SAPIEN XT valve, thus minimising friction between the two structures (Figure 6). By that means it was possible to position the CoreValve without any movement of the dislodged SAPIEN XT valve (Figure 6). Once this step was accomplished, the snare was released and the CoreValve deployed successfully. The final position of the CoreValve was good: the CoreValve distal struts secured the SAPIEN XT valve from any future movement (Figure 7). Haemodynamics were excellent with no residual gradient and no aortic regurgitation.

Follow-up echocardiography showed good valve positioning (Figure 8), minimal paravalvular leak with minimal transvalvular gradient, and significant improvement in the pulmonary hypertension. The patient was discharged five days post procedure and is doing well.

\section{Conflict of interest statement}

A. Segev is a proctor for Edwards Lifesciences and Medtronic, and is on the advisory board of Medtronic. V. Guetta is a proctor for Edwards Lifesciences. The other authors have no conflicts of interest to declare.

\section{References}

1. Holmes DR Jr, Nishimura RA, Grover FL, Brindis RG, Carroll JD, Edwards FH, Peterson ED, Rumsfeld JS, Shahian DM, Thourani VH, Tuzcu EM, Vemulapalli S, Hewitt K, Michaels J, Fitzgerald S, Mack MJ; STS/ACC TVT Registry. Annual Outcomes With Transcatheter Valve Therapy: From the STS/ACC TVT Registry. J Am Coll Cardiol. 2015;66:2813-23.

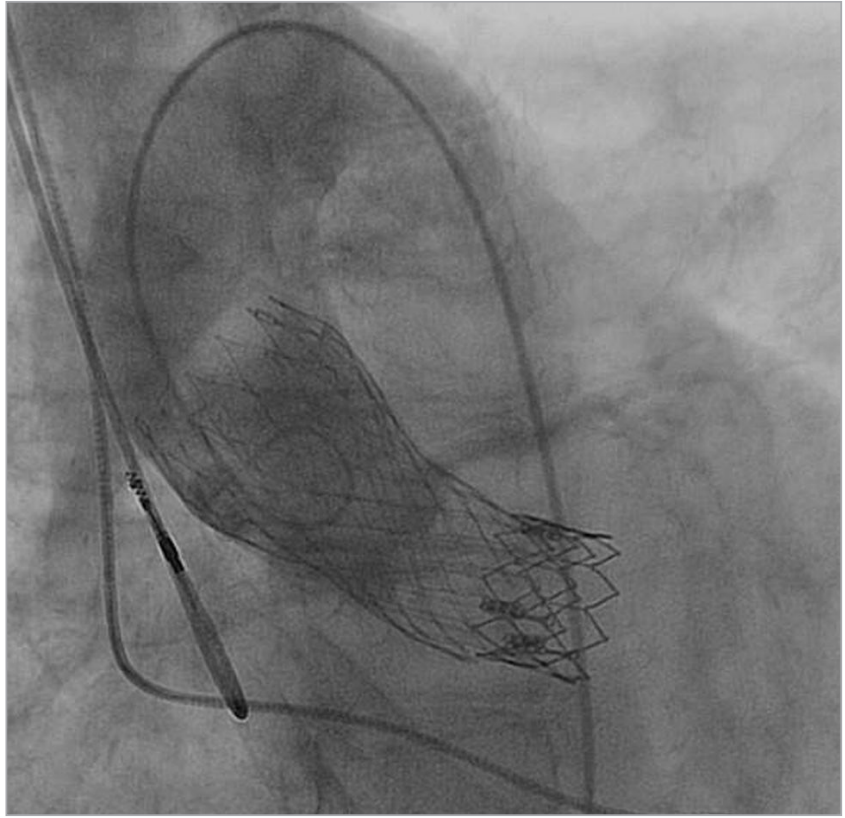

Figure 7. Final result, showing good height of the deployed CoreValve, also securing the SAPIEN XT valve position with the distal CoreValve struts.

2. Ong BH, Chiam PT, Sim DK, Tan TE. Post-implantation transcatheter aortic valve migration in a left ventricular assist device patient with severe aortic insufficiency. Eur Heart J. 2014;35:1616.

3. Seipelt RG, Hanekop G, Schillinger W. Migration of a transcatheter aortic valve in the left ventricular outflow tract. Heart. 2010;96:1949-50.

4. Prakash R, Crouch G, Joseph MX, Bennetts J, Selvanayagam JB, Sinhal A. Very late ventricular displacement of transcatheter aortic valve resulting in severe paravalvular regurgitation. JACC Cardiovasc Interv. 2014;7:e13-5.

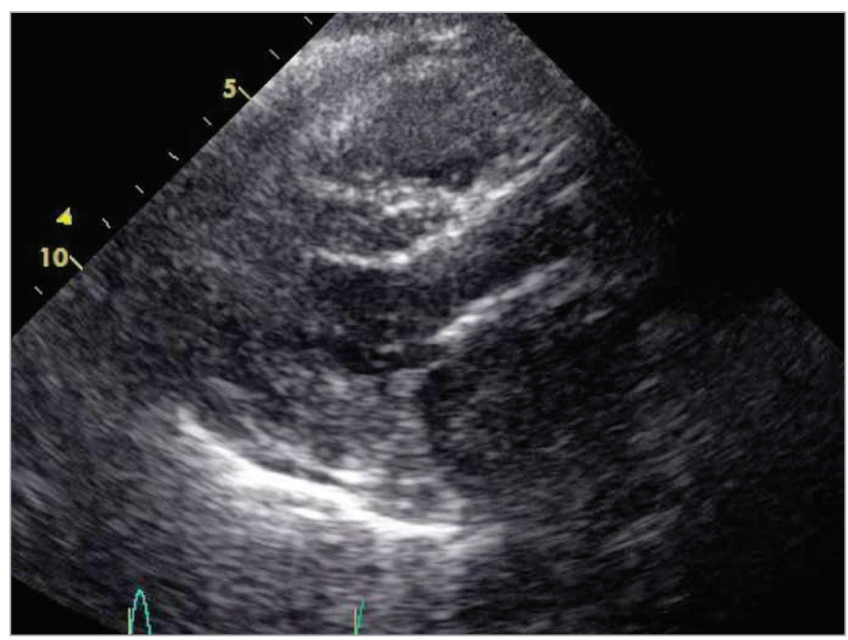

Figure 8. Follow-up transthoracic echocardiography showing both the CoreValve and SAPIEN XT valves without additional movement. 
5. Pang PY, Chiam PT, Chua YL, Sin YK. A survivor of late prosthesis migration and rotation following percutaneous transcatheter aortic valve implantation. Eur J Cardiothorac Surg. 2012;41:1195-6.

6. Nkomo VT, Suri RM, Pislaru SV, Greason KL, Sinak LJ, Holmes DR, Mathew V, Rihal CS. Delayed transcatheter heart valve migration and failure. JACC Cardiovasc Imaging. 2014;7:960-2.

7. AlAli AM, Altwegg L, Horlick EM, Feindel C, Thompson CR, Cheung A, Carere RG, Humphries K, Ye J, Masson JB, Webb JG. Prevention and management of transcatheter balloon-expandable aortic valve malposition. Catheter Cardiovasc Interv. 2008;72:573-8.

8. Astarci P, Desiron Q, Glineur D, El Khoury G. Transapical explantation of an embolized transcatheter valve. Interact Cardiovasc Thorac Surg. 2011;13:1-2.

9. Otalvaro L, Damluji A, Alfonso CE, Williams DB, Heldman AW. Management of transcatheter aortic valve embolization into the left ventricle. J Card Surg. 2015;30:360-3.

10. Eggebrecht H, Mehta RH, Kahlert P, Schymik G, Lefèvre T, Lange R, Macaya C, Mandinov L, Wendler O, Thomas M. Emergent cardiac surgery during transcatheter aortic valve implantation (TAVI): insights from the Edwards SAPIEN Aortic Bioprosthesis European Outcome (SOURCE) registry. EuroIntervention. 2014;10:975-81.

11. Clavel MA, DumontE, PibarotP, Doyle D, De LaRochellière R, Villeneuve J, Bergeron S, Couture C, Rodés-Cabau J. Severe valvular regurgitation and late prosthesis embolization after percutaneous aortic valve implantation. Ann Thorac Surg. 2009;87:618-21.
12. Makkar RR, Jilaihawi H, Chakravarty $\mathrm{T}$, Fontana GP, Kapadia S, Babaliaros V, Cheng W, Thourani VH, Bavaria J, Svensson L, Kodali S, Shiota T, Siegel R, Tuzcu EM, Xu K, Hahn RT, Herrmann HC, Reisman M, Whisenant B, Lim S, Beohar N, Mack M, Teirstein P, Rihal C, Douglas PS, Blackstone E, Pichard A, Webb JG, Leon MB. Determinants and outcomes of acute transcatheter valve-in-valve therapy or embolization: a study of multiple valve implants in the U.S. PARTNER trial (Placement of AoRTic TraNscathetER Valve Trial Edwards SAPIEN Transcatheter Heart Valve). J Am Coll Cardiol. 2013;62:418-30. 13. Dumonteil N, Marcheix B, Grunenwald E, Roncalli J, Massabuau P, Carrie D. Left ventricular embolization of an aortic balloon-expandable bioprosthesis: balloon capture and reimpaction as an alternative to emergent conversion to open-heart surgery. JACC Cardiovasc Interv. 2013;6:308-10.

14. Lauten A, Hamadanchi A, Doenst T, Figulla HR. Late migration of balloon-expandable transcatheter aortic valve. Eur Heart J. 2013;34:2509.

15. Maroto LC, Rodriguez JE, Cobiella J, Silva J. Delayed dislocation of a transapically implanted aortic bioprosthesis. Eur $J$ Cardiothorac Surg. 2009;36:935-7.

16. Naganuma T, Latib A, Agricola E, Alfieri O, Spagnolo P, Colombo A, Maisano F. Late downward dislocation of a balloon expandable valve into the left ventricular outflow tract following transfemoral transcatheter aortic valve implantation. Circ J. 2013;77:1345-7. 